\title{
Trends in primary care DGA \& sedation in NW England
}

\author{
The provision of primary care dental general anaesthesia and sedation in the north west region of England, 1996-1999 \\ by JG Whittle BrDent J 2000; 189:500-502
}

\begin{abstract}
Aim
To investigate trends in the provision of primary care dental general anaesthesia (DGA) and sedation following the new guidance from the General Dental Council.

\author{
Design \\ Cross-sectional analysis of data about the provision of DGA in \\ the General Dental Service and Community Dental Service from \\ $1996 / 97$ to $1998 / 99$.
}

\section{Setting}

The North West Health Region of England.

\section{Method}

The numbers of DGAs in the General Dental Service (GDS) and Community Dental Service (CDS) for the three financial years, 1996/97, 1997/98 and 1998/99 were examined. In addition General Dental Service quarterly information about the numbers of general anaesthetics, sedations requiring another dentist or doctor, and claims for conscious sedation or inhalation sedation from April 1997 to December 1999 was requested from the Dental Practice Board.

\section{Results}

The numbers of DGAs declined by 24 per cent between 1996/97 and 1998/99. Those in the GDS fell from 14,550 in the first quarter of $1997 / 98$ to 3,527 in the first quarter of 1999/2000. The number of claims for sedation, which required another dentist or doctor, increased from 712 in the first quarter of $1997 / 98$ to 2,989 in the same quarter of $1999 / 2000$, while the number of claims for conscious sedation and inhalation sedation increased slightly from 2,847 to 2,963 over the same period.

\section{Conclusions}

The revised General Dental Council guidance has reduced the numbers of DGAs being carried out in both GDS and CDS. The number of sedations involving another dentist or doctor has increased considerably but the new guidance seems to have had little effect on the numbers of patients receiving operated administered conscious sedation and inhalation sedation.

In Brief

- General anaesthetics in the GDS have fallen since the GDC guidance was changed.

- Concern is expressed about the increase in the number of patients under 18 receiving sedation administered by another dentist or doctor.

- There is scope for a considerable increase in relative analgesia (inhalation sedation).

- The savings in the GDS should be used to improve standards.

\section{Comment}

The provision of dental general anaespractice has received great attention particularly over the past 10 years. The Poswillo report in 1990 recommended improved facilities for DGA in primary care and the promotion of conscious sedation as a safe alternative. In May 1998 concerns were raised once again about the safe provision of DGA and sedation and subsequently in November of the same year the General Dental Council issued revised guidelines for the provision of DGA and sedation in primary care. It was expected as a result of the new guidelines that there would be a significant reduction in the provision of general anaesthesia in primary care and as a consequence of this that there would be a parallel increase in sedation services.

Whittle's paper sets out to investigate whether changes to service provision did indeed occur. Data available from the General Dental Service (GDS) and Community Dental Services in the North West
Region of England was considered for the financial years $1996 / 97$ to $1999 / 2000$. A marked reduction in the number of general anaesthetics carried out was reported during the study period, with a significant reduction in GDS provision being evident in the period immediately following the publication of the guidelines. The reduction in cases treated was mirrored by a similar fall in the number of general dental practitioners (GDP) providing a DGA facility. These findings were assumed to be caused by GDPs being unwilling or unable to provide general anaesthesia and to a possible change in prescribing patterns. With this fall in DGA provision it was expected that a significant increase in sedation claims would have been witnessed. Whittle's paper illustrates such a finding, however the increase in sedation claims fell short of the reduced cases being treated under general anaesthetic.

The author considers reasons for these changes in service provision and attempts to suggest how cases that were being treated under general anaesthetic prior to November 1998 are now being managed. Financial considerations are also discussed and recommendations are made for further research into this area of patient care.

This paper is timely in the present climate, where further restrictions have been placed on the dental profession in the delivery of patient care under general anaesthesia. Through his investigation Whittle highlights how service provision is effected by changing professional guidelines and how this forces us to look at our clinical practice in a critical light. He also emphasises the need for resources for DGA within the GDS to be appropriately redistributed in order to enable appropriate care to be delivered.

\section{Kathy Wilson}

Senior Dental Officer (Specialist Clinical Services), South Tyneside Community Dental

Service, South Tyneside Health Care Trust and Staff Grade in Sedation, Newcastle Dental

School, Newcastle upon Tyne 